\title{
Commentary
}

\section{Traditional Phytochemistry: Identification of Drug by 'Taste'}

\author{
Kalpana Joshi ${ }^{1}$, Alex Hankey ${ }^{2}$ and Bhushan Patwardhan ${ }^{1}$ \\ ${ }^{1}$ Interdisciplinary School of Health Sciences, University of Pune, Pune 411007, India and \\ ${ }^{2}$ Hethe House, Cowden, Kent TN8 7DZ, UK
}

\begin{abstract}
Ayurveda, the system of traditional medicine from India, holds that 'Rasa', a concept roughly corresponding to taste, is a basis for identifying pharmacological properties of plants and other materia medica used in Dravyaguna-its system of phytomedicine. This idea has recently found support in studies of ibuprofen, the pharmacological properties of which are similar to those of oleocanthal, because the two substances have very similar tastes. This paper discusses a possible scientific approach to understanding the Ayurvedic (hypo)thesis in terms of the stereochemical basis of both pharamacoactivity and taste, and the numbers of possible pharmaco-active compounds that 'Rasa' may be able to distinguish. We conclude that molecules binding to a specific enzyme active site should have their own 'Rasa', and that the number of different subjectively experienced 'tastes' is more than enough to distinguish between molecular shapes binding to all enzyme active sites in the body.
\end{abstract}

Keywords: ayurveda - drug discovery - ibruprofen - oleocanthal - taste

In a recent submission to Nature (1), Beauchamp et al. relate the pharmacological activities of Ibuprofen and Oleocanthal to their similarities of taste. They point out that both Oleocanthal, from olive oil, and solutions of Ibuprofen, a non-steroidal antiinflammatory drug, induce similar strong stinging sensations in the throat (1). Despite not being entirely similar structurally, both molecules are anti-inflammatory and share similar profiles, being COX-1 and COX-2 inhibitors. This is one of the rare scientific reports noting common pharmacological activity for compounds with similar taste. As such, it is consistent with the suggestion in traditional Ayurveda that substances' similarities of 'Rasa' may indicate similar pharmacological activity (2).

At this time, Ayurveda (3) and its core concepts are being increasingly subjected to scientific scrutiny $(4,5)$. Their scientific robustness is becoming better appreciated $(6,7)$, hence an evaluation of Ayurveda's means of drug identification. The Sanskrit word 'Rasa' is usually rendered into English as 'taste' for want of a better word, but it possesses a deeper and more subtle meaning. Rasa refers to the total subjective experience arising from putting the substance in the mouth, including not only the six primary tastes recognized by Ayurveda (sweet, sour, salty, bitter, pungent and astringent), but also the 'flavours' experienced by means of retronasal olfaction (nasal

For reprints and all correspondence: Alex Hankey, Hethe House, Cowden, Kent TN8 7DZ, UK. E-mail: Alexhank@dircon.co.uk smell receptor stimulation by food warmed in the mouth), the more acrid, chemesthesis irritation sense referred to above, and even more subtle associations available to rare individuals such as the ancient rishis of the Vedic civilization. The latter notwithstanding, 'Rasa' refers to a complex totality of experience arising from all the perceptory interactions of the material with sensors in the mouth and nasal passages, taste buds, olfactory and chemesthetic receptors. At a simple level, the six Rasas are said to respond in a precise way to particular qualities, or 'panchamahabhuttas', of plant material tasted (see Fig. 1). Identification of pharmacoactivity would require a far greater sensitivity, the basis for which we consider in this commentary.

Over the past five millennia or more, oriental traditions of medicine such as Ayurveda and Traditional Chinese Medicine have identified and prepared large numbers of effective therapeutic preparations, as modern scientific evaluations of their efficacy amply demonstrate (8). How they were able to do so is not at all understood. If it were, it might well assist in future identification of potential sources of drugs. Ayurveda's claim that 'Rasa' provides an effective means of identification, though seemingly simplistic, merits deeper scientific analysis, to see what substance there may be to it. It is apparently supported by the comparison of Oleocanthal and Ibuprofen.

Other support comes from Heinrich (9) who states that their combination of taste and smell are important selection criteria 


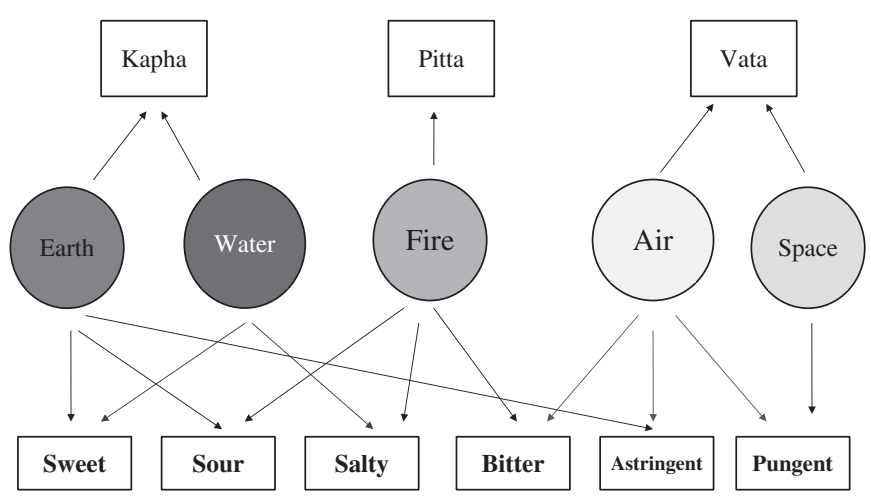

Figure 1. The figure shows one relationship between taste and physiological property proposed in Ayurveda, using its various classifications of matter, taste and organism regulation: the five qualities attributed to condensed matter (Panchamahabhutta) mediate between the six tastes (Shadrasa) and the three principle classes of organism regulation (Tridosha). The Tridosha are seen as emerging from the Panchamahabhutta as life animates condensed matter, while the Shadrasa are sensory attributes of each of the Panchamahabhutta, permitting them to be experienced through the five senses (or Panchagyanendriya-not depicted).

for indigenous plants to have medicinal properties—or lack of them-a point consistent with Ayurveda's position. Further support may come from sensory anthropology: Shepard (10) states that sensation has been explored as a fruitful but poorly examined domain of cross-cultural research, commenting that the role of the senses in medicinal plant therapy has benefited greatly from theoretical insights gleaned from sensory science. Fischer (11) has worked extensively on the psychology of taste, correlating taste thresholds and just-noticeable-differences with psychopathology, and reasons for differing taste sensitivities at different periods of life. This commentary presents a deeper analysis of the molecular biology of 'taste' to examine its possible scientific basis.

To pursue Ayurveda's thesis further, a molecule's 'Rasa' must be related more precisely to its biochemical structure, and then to its pharmacological properties. As stated above, we shall consider the total subjective experience of taste, 'Rasa', to include, first, the properties of taste experienced through taste buds in the mouth and their corresponding neural pathways to the brain (12), second, olfactory sensations, generated retronasally after food has been warmed in the mouth, and, third, the chemesthetic sense. Identities of Ayurvedic 'Rasas' thus have contributions from all of these. We first consider taste and smell separately, and then combine them.

The number of independent contributions to the sensation of taste is a complex question. The classic kinds of taste through taste bud are sweet, sour, salty, bitter and umami (13), but it is accepted that there are more 'subjective dimensions' to taste than these. In addition there are sensations of: 'hot' (or 'pungent') as in mustard or chili, astringent as in turmeric, alkali, metallic and meaty taste sensations (14), and the chemesthetic (or trigeminal) sense. For these, there are no taste buds, so other pathways transmit their information to the brain. A reasonable estimate of the number of independent dimensions to the subjective sensation of taste (without regard to olfaction) is therefore $\sim 10$.

With regard to smell, Buck and Axel (15-17) identified a multigene family of transmembrane olfactory receptor proteins with over 1000 members, of which up to 300 may be active in humans. [In addition, Dulac and Axel identified a different multigene family encoding putative pheromone receptors in the vomeronasal organ (18).] While it is true to say that many structurally different molecules may stimulate any given receptor protein, and that many proteins may be stimulated by a given molecular species, this multiplicity begins to explain animals' extraordinary olfactory sensitivity. Primates distinguish many enantiomer pairs (19). Bees (20), rats and dogs can detect specific molecules in explosives (21) and contraband (22), while dogs can sniff out bladder cancers from urine samples (23). Such specificity alone supports the idea that the olfactory sense of a suitably sensitive person could distinguish between different molecules binding to different enzyme active sites, i.e. with different pharmacological activity.

In the case of the sense of sight, there are three wellcharacterized photosensitive molecules, yielding different, overlapping absorption spectra in the 'red', 'green' and 'blue' regions of the electromagnetic spectrum. The physics of how these combine to yield a visual sensitivity capable of discriminating some half a million color mixtures (mostly in 'earth' and 'forest'/'grassland' shades) is well understood and the basis for all color engineering applications, e.g. the original Polaroid instant color-print camera.

How the corresponding engineering problem works for the combination of gustation and olfaction constituting 'Rasa' is not so well characterized. The dimensionality analogous to the number for color vision is clearly much larger, and should yield a correspondingly greater number of discriminatable values. To the 10 dimensions identified for gustation, must be added the number for olfaction. The problem in estimating the number of olfaction dimensions is that, although the number of genes and corresponding transmembrane proteins in the olfactory epithelia (and vomeronasal organ) is large, they are not where olfactory cognition and discrimination take place. That is in the olfactory cortex, with its complex, multilayer processing, not dissimilar to that in the visual cortex. The number of dimensions is given by the number of distinct kinds of neural signal transmitted from olfactory receptor cells to the olfactory cortex, a number not necessarily equal to the number of kinds of receptor proteins, for if different receptor proteins in the olfactory epithelia lead to identical, or sufficiently similar, signals being transmitted to the olfactory cortex, their difference will not increase olfactory discrimination. Indeed, it is possible that the reason for the large number of different olfactory receptor proteins is to increase the number of different molecules that will produce a signal, and be detected, and not necessarily to increase olfactory discriminatory ability. The aim may be to increase overall sensitivity, rather than discrimination.

In estimating the subjective dimensionality of olfaction, we therefore need to look further for some other clue. Another 
source of information for the number of distinguishable signals a single organ can transmit to the brain is the number of distinct ways organ health is monitored and compensated (24). Grakov (25) has shown that organs transmit to the brain up to 15 distinguishable kinds of neural signal concerning their state of health, and that the brain can accurately and reproducibly estimate 50-60 levels of magnitude for each such signal. These are not consciously cognized, and only appear as a secondary effect in impairments to visual, color discrimination. Color discrimination is similar, three dimensions including gray scale lead to an ability to discriminate $\sim 5 \times 10^{5}$ colors or 80 per dimension. Most organs transmit at least 10 distinct signals of this kind (24). A reasonable lower bound for the number of classes of variable magnitude neural signal the olfactory cortex cognitively discriminates is therefore between 5 and 10. Combining the estimates of taste and smell dimensionality yields a conservative estimate of 15-20 for the dimensionality of 'Rasa'.

How can these be used to estimate the number of discriminatable 'Rasa' sensations? For smell, it is recognized that inexperienced subjects can only distinguish four levels of smell intensity: none-weak-moderate-strong. (12, p. 137). Since our concern is lower limits, this may be used for the sensitivity of each of the estimated 15-20 dimensions: four levels of sensitivity for each dimension (cf. 50-60 for organ health). If, in identifying a substance's 'rasa', the brain assesses the stimulation of all taste and smell receptors, then, even with only four intensity levels, the 15-20 dimensions yield $4^{15}-4^{20}$ separately identifiable Rasas. This is between 1 billion and 1 trillion $\left(10^{9}-10^{12}\right)$.

Now consider 'taste' pharmacologically, in terms of active sites to which binding may occur. Molecules bind to an enzyme active site because their conformation including size and shape are correct, and their chemical moieties are in the right places to produce binding. Such properties are all but identical to those enabling a molecule to bind to smell and taste receptors, and so acquire its specific 'Rasa', or subjectively identified taste: in smell receptors, a molecule's specific size and shape activate the receptor, while in taste receptors specific chemical reactivity may be more involved.

Given that the criteria for molecules to bind to specific enzyme active sites are so similar to criteria for their binding to taste and smell receptors in the mouth and nasal epithelia, it is difficult to conceive that a molecule capable of binding to a particular site either as a substrate or a drug would not possess a different 'Rasa' from another molecule binding to a different enzyme active site. Two such sites would have to be differently structured in order to bind their two natural molecular substrates appropriately, so the proposal that a combination of 'taste' and 'smell' should be able to distinguish the two seems plausible.

To express this quantitatively: the number of identifiable 'tastes', conservatively estimated above at $10^{9}-10^{12}$, is far greater than the number of active sites of all the enzymes in the human body. Each such site probably has its own identifiable 'Rasa' taste. Rasa provides enough potentially available information to distinguish molecules of all possible pharmacoactivities acting on the physiology, though, of course, some active sites may be so similar that tastes of molecules binding to them are indistinguishable.

\section{Conclusions}

Notwithstanding such complications, Ayurveda's correspondence of 'Rasa' with pharmacological activity assumes a new significance: instead of being too limited to distinguish all the kinds of molecule that may influence the functioning of enzyme active sites, it should be capable of doing so. It is therefore possible that Ayurveda's traditional approach could provide new leads in phytochemical drug discovery. Using 'taste' as an additional tool, new phytochemicals of desired therapeutic activity might be more rapidly identified. Of course, though this reasoning provides corroborative support for one aspect of Ayurveda, it still does not solve the riddle of how the ancients identified the pharmacoactivities of so many species of plant, their relative potency and individual properties. That remains an open question for further investigation.

Though Beauchamp et al. (1) did not refer to the traditional concept of identification of pharmacoactivity through taste; their observations support it and offer new directions to research validating traditional concepts and medicines. Their work may also facilitate the possibility of discovering new drugs based on traditional knowledge (26). It also supports the thesis that complementary medical systems can be of rigorous scientific value (27), in particular that some of Ayurveda's unique concepts are worth examining in depth for their implications for biology and medicine (28).

\section{References}

1. Beauchamp GK, Keast RS, Morel D, Lin J, Pika J, Han Q, et al. Breslin phytochemistry: ibuprofen-like activity in extra-virgin olive oil. Nature 2005;437:45-6.

2. Valiathan MS. The Legacy of Caraka. Hyderabad, India: Orient Longman, 2004.

3. Sharma H, Clark C. Contemporary Ayurveda. Philadelphia: Churchill Livingstone, 1998.

4. Bodeker G. Evaluating Ayurveda. J Altern Complement Med 2001;7: 389-92.

5. Chopra A, Doiphode V. Ayurvedic medicine: core concept, therapeutic principles, and current relevance. Med Clin North Am 2002;86:75-89.

6. Hankey A. The scientific value of Ayurveda. J Altern Complement Med 2005;11:221-5.

7. Patwardhan B, Joshi K, Chopra A. Classification of human population based on Ayurvedic concept of Prakriti. J Altern Complement Med 2005;11:349-53.

8. Patwardhan B, Gautam M. Botanical immunodrugs: scope and opportunities. Drug Discov Today 2005;10:495-502.

9. Heinrich M. Ethnobotany and natural products: the search for new molecules, new treatments of old diseases or a better understanding of indigenous cultures? Curr Top Med Chem 2003;3:141-54.

10. Shepard G. A sensory ecology of medicinal plant therapy in two Amazonian societies. Am Anthropol 2004;106:252-66.

11. Fischer R. Psychology of taste. In: Ohloff G, Thomas AE (eds). Gustation and Olfaction, New York: Academic Press, 1971, 187-237.

12. Lawless HT. Olfactory psychophysics. In: Beauchamp GK, Bartoshuk L (eds). Tasting and Smelling. Chapter 4, San Diego: Academic Press, 1997, 125-74. 
13. Brand JG. Biophysics of taste. In: Beauchamp GK, Bartoshuk L (eds). Tasting and Smelling, Chapter 1, San Diego: Academic Press, 1997, 1-24.

14. Halpern BP. Psychophysics of taste. In: Beauchamp GK, Bartoshuk L (eds). Tasting and Smelling. Chapter 3, San Diego: Academic Press, 1997, 77-123.

15. Buck L, Axel A. A novel multigene family may encode odorant receptors: a molecular basis for odor recognition. Cell 1991;65:175-87. Also: Comment, Cell 2004;116(2 Suppl):S117-9.

16. Chess A, Buck L, Dowling MM, Axel R, Ngai J. Molecular biology of smell: expression of the multigene family encoding putative odorant receptors. Cold Spring Harb Symp Quant Biol 1992;57:505-16.

17. Ngai J, Dowling MM, Buck L, Axel R, Chess A. The family of genes encoding odorant receptors in the channel catfish. Cell 1993;72: $657-66$.

18. Dulac C, Axel R. A novel family of genes encoding putative pheromone receptors in mammals. Cell 1995;83:195-206.

19. Laska M, Genzel D, Wieser A. The number of functional olfactory receptor genes and the relative size of olfactory brain structures are poor predictors of olfactory discrimination performance with enantiomers. Chem Senses 2005;30:171-5.

20. Rodacy PJ, Bender SFA, Bromenshenk JJ, Henderson CB, Bender G. The Training and Deployment of Honeybees to Detect Explosives and Other Agents of Harm. Proceedings of SPIE (The International Society for Optical Engineering), AeroSense CBS Work, April 2002, Vol. 4742-54.
21. Connelly JM, Curby WA, Fox FT, Hallowell SF. Detection of hidden explosives. In: Beveridge A (ed). Forensic Investigation of Explosions. London, UK: Taylor and Francis, 1998, 45-71.

22. Otto J, Brown MF, Long W. Training rats to search and alert on contraband odors. Appl Anim Behav Sci 2002;77:217-32.

23. Willis CM, Church SM, Guest CM, Cook WA, McCarthy N, Branbury AJ, et al. Olfactory detection of human bladder cancer by dogs: proof of principle study. Br Med J 2004;329:712.

24. Ewing G, Ewing E, Hankey A. Virtual Scanning: a new method of health assessment and treatment. Part I: assessment. J Altern Complement Med 2006 (in press).

25. Grakov I. Description of Virtual Scanning system for operators. Sochi, Russia: Mimex 2002. English translation available at: http://www.psychoenergetic.com/strannik/indexuk.html/.

26. Patwardhan B, Vaidya ADB, Chorghade M. Ayurveda and natural product drug discovery. Curr Sci 2004;86:789-99.

27. Cooper EL. Complementary and alternative medicine, when rigorous, can be science. Evid Based Complement Alternat Med 2004; $1: 1-5$.

28. Hankey A. CAM modalities can stimulate advances in theoretical biology. Evid Based Complement Alternat Med 2005;2:5-12.

Received November 7, 2005; accepted August 22, 2006 


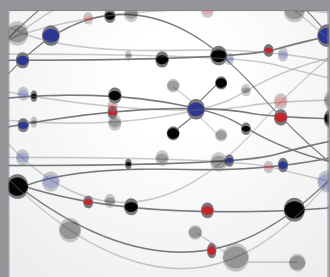

The Scientific World Journal
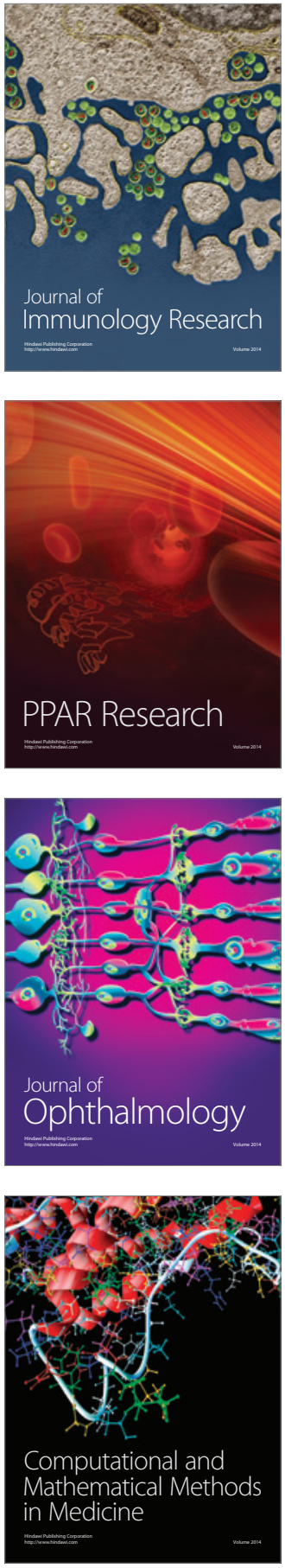

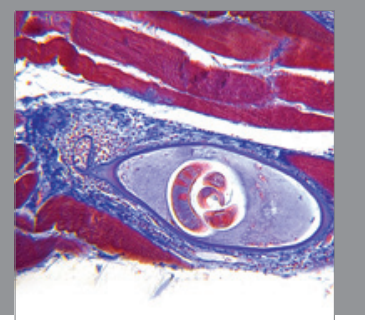

Gastroenterology

Research and Practice
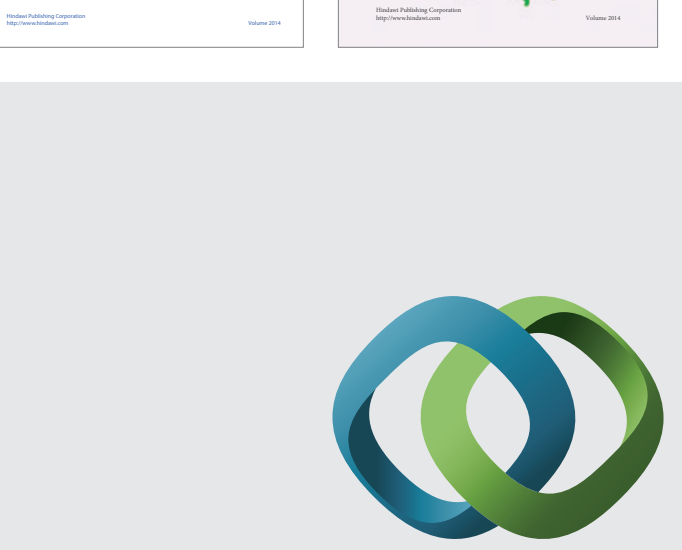

\section{Hindawi}

Submit your manuscripts at

http://www.hindawi.com
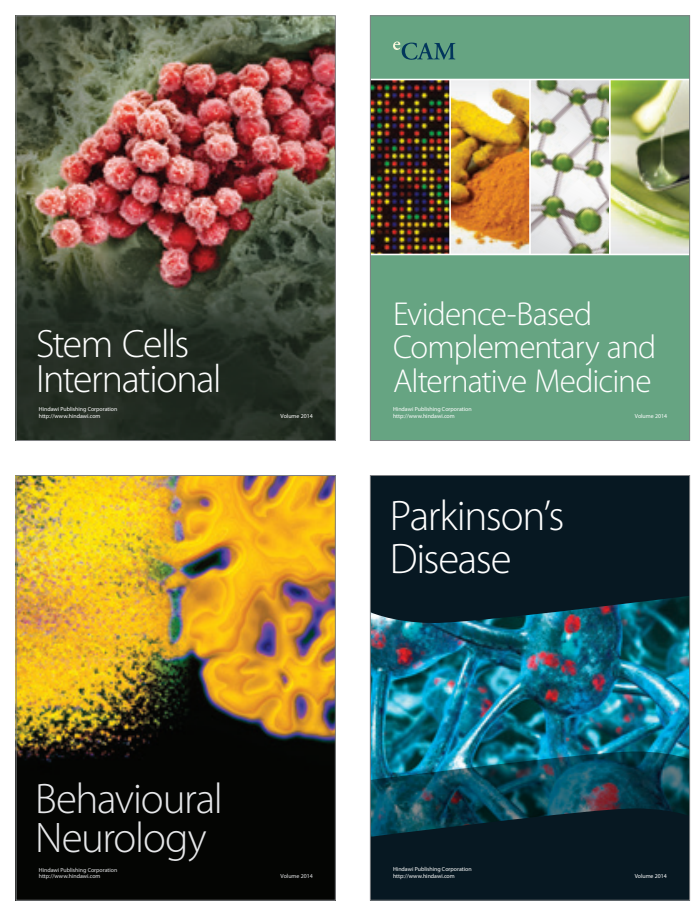

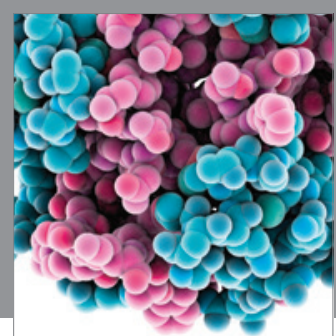

Journal of
Diabetes Research

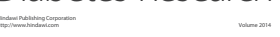

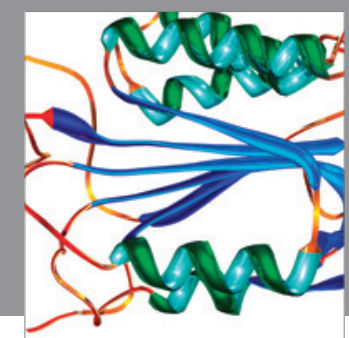

Disease Markers
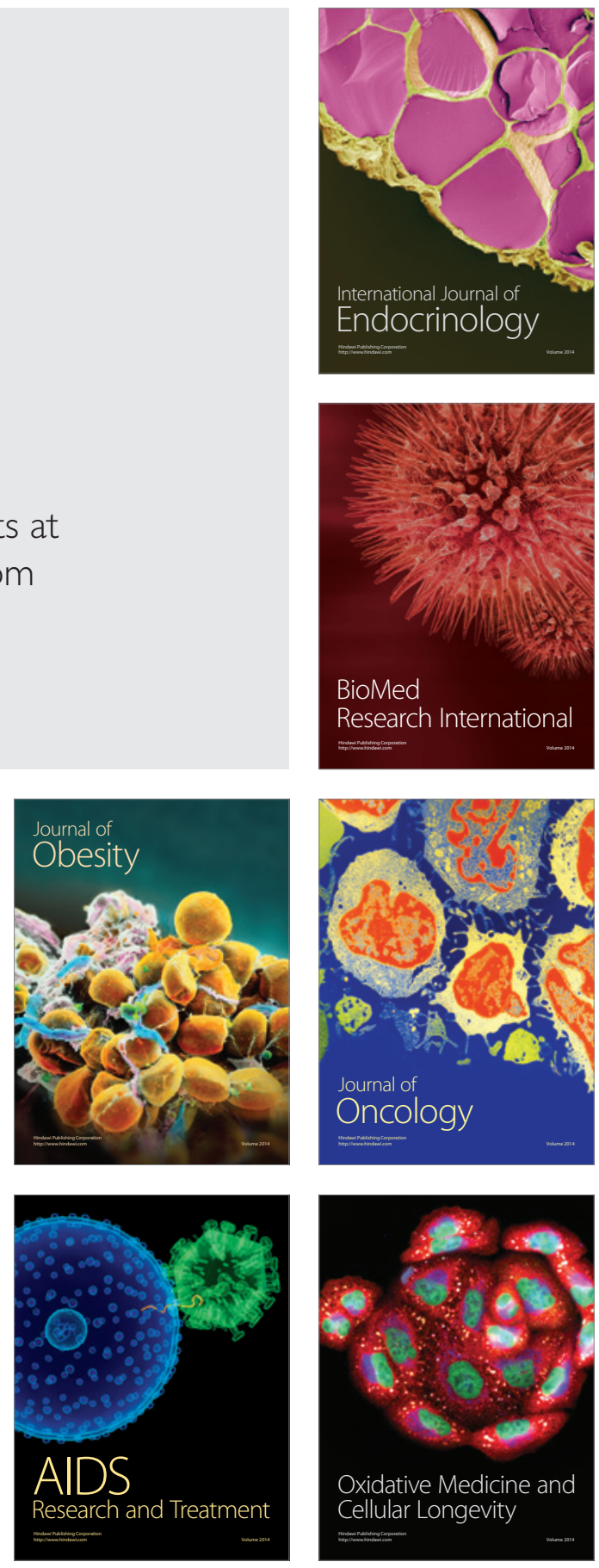